\title{
APPLICATION OF GEO-INFORMATICS ENGINEERING TO ESTIMATE ABOVE-GROUND CARBON SEQUESTRATION
}

\author{
Teerawong Laosuwan $^{1 *}-$ Yannawut Uttaruk $^{2}$ - Tanutdech Rotjanakusol ${ }^{1}-$ Kusuma Arsasana $^{3}$ \\ ${ }^{1}$ Department of Physics, Faculty Science, Mahasarakham University, Khamriang, Kantarawichai, Mahasarakham, \\ 44150, Thailand. \\ ${ }^{2}$ Department of Biology, Faculty Science, Mahasarakham University, Khamriang, Kantarawichai, Mahasarakham, \\ 44150, Thailand. \\ ${ }^{3}$ Department of Geo-informatics, Faculty of Informatics, Mahasarakham University, Khamriang, Kantarawichai, \\ Mahasarakham, 44150, Thailand.
}

\begin{tabular}{l} 
ARTICLE INFO \\
\hline Article history: \\
Received: 14.04 .2016$. \\
Accepted: 22.02 .2017$. \\
\hline Keywords: \\
Geo-informatics engineering \\
Remote sensing \\
Estimate \\
Above-ground carbon sequestration \\
\hline
\end{tabular}

DOI: https://doi.org/10.30765/er.38.3.7

\section{Introduction}

The levels of carbon dioxide in the atmosphere nowadays are not only higher due to the burning of fossil fuels such as oil, coal and natural gas by human hands, but also the deforestation. Forestry areas especially several tropical rain forests in developing countries are destroyed for trading or agricultural purposes [1-3]. The destruction of forests produces

\begin{abstract}
:
This research aims to estimate above-ground carbon sequestration of orchards by using the data collected from Landsat 8 OLI. Regression equations are applied to study the relationship between the amount of above-ground carbon sequestration and vegetation indices from Landsat 8 OLI, in which the data was collected in 2015 in 3 methods: 1) Difference Vegetation Index (DVI), 2) Green Vegetation Index (GVI), and 3) Simple Ratio (SR). The results are as follows: 1) By DVI method, it results in the equation $y=0.3184 e^{0.0482 x}$ and the coefficient of determination $R^{2}=0.8457$. The amount of the above-ground sequestration calculation's result is 213.176 tons per rai. 2) Using the GVI method, it results in the equation $y=$ $0.2619 e^{0.0489 x}$ and the coefficient of determination $R^{2}=0.8763$. The amount of the above-ground sequestration calculation's result is 220.510 tons per rai. 3) Using the SR method, it results in the equation $y=0.8900 e^{0.0469 x}$ and the coefficient of determination $R^{2}=0.7748$. The amount of the above-ground sequestration calculation's result is 234.229 tons per rai.
\end{abstract}

large amounts of greenhouse gases. When the trees are burned or destroyed, the carbon dioxide collected in those trees will be emitted to the atmosphere. In addition, the amounts of carbon dioxide in the world's atmosphere have been excessive since the past century until now and they tend to increase continually. At present, the global concentration of carbon dioxide in the atmosphere has reached 383 ppm [4]. The increase of carbon dioxide in the

\footnotetext{
* Corresponding author. Tel.: +66-4375-433 ext. 1135

E-mail address: teerawong@msu.ac.th
} 
atmosphere is a significant factor that causes the greenhouse effect. It has a profound impact on the rise of the earth's temperature. Forests play an important role in changing of carbon dioxide levels in the atmosphere as $20 \%$ of carbon dioxide increase caused by the loss of carbon in biomass burning due to deforestation and loss of soil carbon due to the land use [5-8].

In addition, trees can absorb carbon dioxide from the atmosphere by photosynthesis process and being stocked in biomass forms which include aboveground parts such as stems, branches, and leaves; and underground parts such as roots. The process makes carbon stay in the trees until they are cut down $[5,6,9,10]$. Thus, cutting off trees should be reduced, while forestry areas should be more increased by announcing forest protected areas. However, the estimation of carbon storage of wide forest areas by surveying is difficult and expensive. Therefore, for this reason, geo-informatics engineering by application of remote sensing is applied to calculate the amounts of carbon storage in forestry areas [1117]. This method makes it very convenient and reduces the cost of estimating the amounts of carbon storage in forestry areas.

In Thailand, most researches focus on the estimation of carbon storage of forestry areas and forest parks. Nevertheless, the data collection of carbon storage in fruit orchards has not been brought to focus. Therefore, this research aims to study the amounts of the above-ground carbon sequestration by using remote sensing technology of orchards in Sang Kho sub district, Phu Phan district, Sakon Nakhon Province in northeast Thailand

\section{Materials and Methods}

\subsection{Data Preparation from remote sensing}

This research used the data from Landsat 8 OLI, Path 127 Row 48 dated on the 8th of January in 2016 (Fig. 1). The procedures are as follows (Fig. 2):

1) The image data covering the area of study was chosen. Then the geometric correction was applied to correct the image data.

2) The Top of Atmosphere (ToA) reflectance was adjusted to reduce the mistakes of the energy reflected from objects on the earth to the data recorder based on the current environmental conditions including the weather, landscape, temperature, and angle of incident by using equation 1 and equations 2 [18-20].

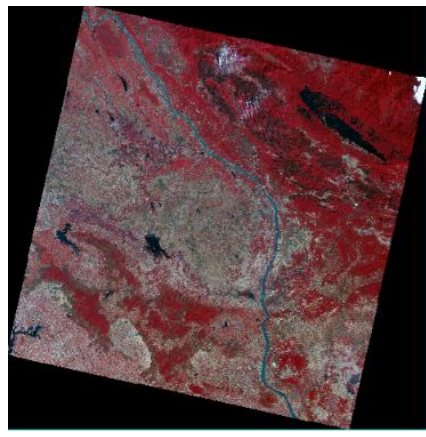

Figure 1. Landsat 8 OLI, Path 127 Row 48.

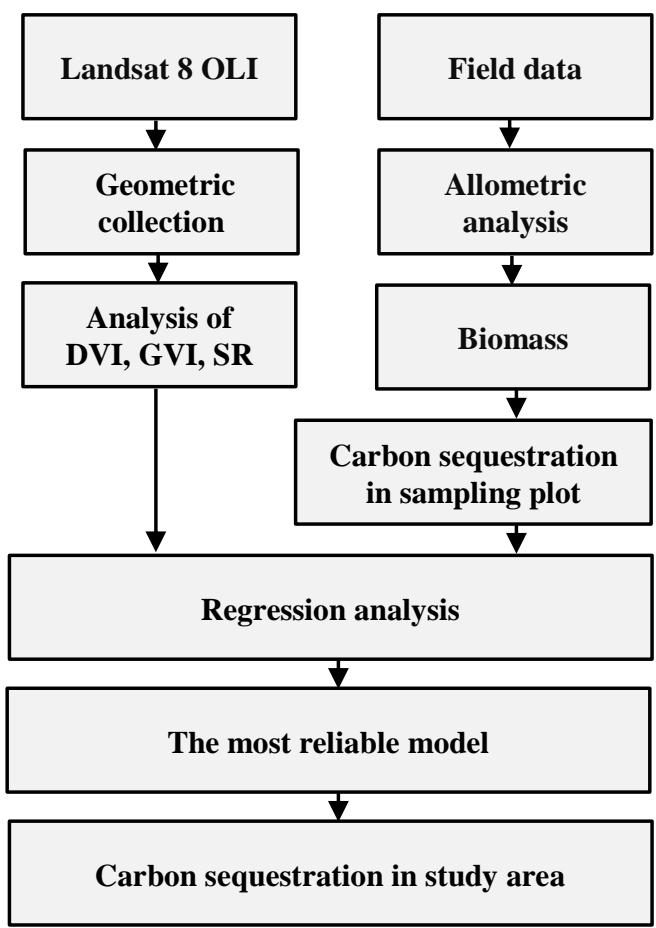

Figure 2. Flowchart of the study.

$$
L_{\lambda}=\text { Grescale } * \text { Qcal }+ \text { Brescale }
$$

Where:

Grescale $=\frac{\operatorname{LMAX}_{\lambda}-\operatorname{LMIN}_{\lambda}}{\text { Qcalmax }- \text { Qcalmin }}$

Brescale $=\operatorname{LMIN}_{\lambda}-\left(\frac{\operatorname{LMAX}_{\lambda}-\operatorname{LMIN}_{\lambda}}{\text { Qcalmax }- \text { Qcalmin }}\right) \times$ Qcalmin

Where:

$L_{\lambda}=$ Spectral radiance at the sensor's aperture

$\left[\mathrm{W} /\left(\mathrm{m}^{2} \mathrm{sr} \mu \mathrm{m}\right)\right]$,

Qcal $=$ Quantized calibrated pixel value [DN],

Qcalmin $=$ Minimum quantized calibrated pixel value corresponding $\operatorname{LMIN}_{\lambda}$, 
Qcalmax = Maximum quantized calibrated pixel value corresponding $L M A X_{\lambda}$,

$\operatorname{LMIN}_{\lambda}=$ Spectral at sensor radiance that is scaled to Qcalmin [W/( $\left.\left.\mathrm{m}^{2} \mathrm{sr} \mu \mathrm{m}\right)\right]$,

$\operatorname{LMAX}_{\lambda}=$ Spectral at sensor radiance that is scaled to Qcalmax [W/( $\left.\mathrm{m}^{2} \mathrm{sr} \mu \mathrm{m}\right)$ ],

Grescale $=$ Band specific rescaling gain factor $\left[\left(\mathrm{W} /\left(\mathrm{m}^{2} \mathrm{sr} \mu \mathrm{m}\right)\right) / \mathrm{DN}\right]$,

Brescale $=$ Band specific rescaling bias factor $\left[\mathrm{W} /\left(\mathrm{m}^{2} \mathrm{sr} \mu \mathrm{m}\right)\right]$.

$$
\rho_{\lambda}=\frac{\pi \times L_{\lambda} \times d^{2}}{E_{S U N_{\lambda}} \times \cos \theta_{s}}
$$

Where:

$\rho_{\lambda}=$ Unitless planetary reflectance,

$\pi=3.14$,

$L_{\lambda}=$ Spectral radiance at sensor's aperture

$\left(\mathrm{Wm}^{-2} \mathrm{sr}^{-1} \mu \mathrm{m}^{-1}\right.$ ),

$d=$ Earth-sun distance in astronomical units,

$E_{S U N_{\lambda}}=$ Mean solar exoatmospheric irradiances,

$\theta_{s}=$ Solar zenith angle.

3) The pixel of the corrected data from the previous steps was chosen in the same spot of the permanent plots for data collection. After that, the data was analyzed together with the DVI, GVI and SR by applying equations 3 to equations 5 [21-25]. Incidentally, the values of the DVI, GVI and SR between 0 to 1 would be the vegetation. If the value was equal to or less than 0 and 0 , it was nonvegetation areas. Moreover, in this study Fractional Cover (FC) (equation 6) was used to set up data and classify plants that were from 0 to 100 .

$$
D V I=N I R-R E D
$$

Where:

$$
\begin{aligned}
& N I R=\text { Near Infrared Band } \\
& R E D=\text { Red band }
\end{aligned}
$$

$$
\begin{aligned}
& G V I=-(0.2848 \cdot \text { Band } 2)-(0.2435 \\
& \text { Band3 })-(0.5436 \cdot \text { Band } 4)+(0.7243 \\
& \text { Band } 5)+(0.0840 \cdot \text { Band } 6)+(0.1800
\end{aligned}
$$$$
\text { Band 7) }
$$

Where:

$$
\begin{aligned}
& \text { Band }= \text { Band } 2 \text { to Band } 7 \text { of Landsat } 8 \\
& \text { OLI }(0.45-2.29 \text { micrometers })
\end{aligned}
$$

$$
S R=N I R / R E D
$$

Where:

$N I R=$ Near Infrared Band

$R E D=$ Red band.

$$
F C=\frac{\left(V I-V I_{\text {open }}\right)}{\left(V I_{\text {canopy }}-V I_{\text {open }}\right)} \times 100
$$

Where:

$F C=$ Tree canopy fractional cover,

$V I=$ Vegetation index,

$V I_{\text {open }}=$ Vegetation index of open areas,

$V I_{\text {canopy }}=$ Vegetation index of tree canopy.

\subsection{Preparation for Field Work}

In this research, 22 permanent plots with $20 \mathrm{~m}$ x 20 $m$ were created as the simulated orchards of the study area which is 72.20 Rai (6.25 rai $=1$ hectare). After that the data of types and numbers of big trees with $4.5 \mathrm{~cm}$ : DBH (Diameter at Breast Height) was collected. This process also included tree height measurement. The survey data was recorded into the data recording form. Then Allometric equation (equation 7) was used for plants in agroforestry in Thailand [4] to calculate the amounts of aboveground biomass.

$$
\begin{array}{ll}
W s=0.0389\left(D^{2} H\right)^{(0.9417)} & r^{2}=0.9106 \\
W b=0.0678\left(D^{2} H\right)^{(0.6618)} & r^{2}=0.8347 \\
W l=0.0084\left(D^{2} H\right)^{(0.7660)} & r^{2}=0.9109
\end{array}
$$

Where:

$W s=$ Stem; $W b=$ Branch; $W l=$ Leaf.

\subsection{The Data Analysis}

The estimation of the above-ground carbon sequestration by using the data collected from Landsat $8 \mathrm{OLI}$ is as follows:

1) The regression equation was used to analyze the relationship between the amounts of the aboveground carbon storage and spectral reflectance rate in 
connection with the data of vegetation indices from Landsat 8 OLI in 2015 such as the DVI, GVI and SR. 2) The data results were compared to determine the most suitable equation to estimate the above-ground carbon sequestration in orchards in Sang Kho sub district, Phu Phan district, Sakon Nakhon Province in northeast Thailand.

\section{The results and discussion}

In this study, the results of satellite data from Landsat 8 OLI data through the correction process (ToA) can be presented in Fig. 3.

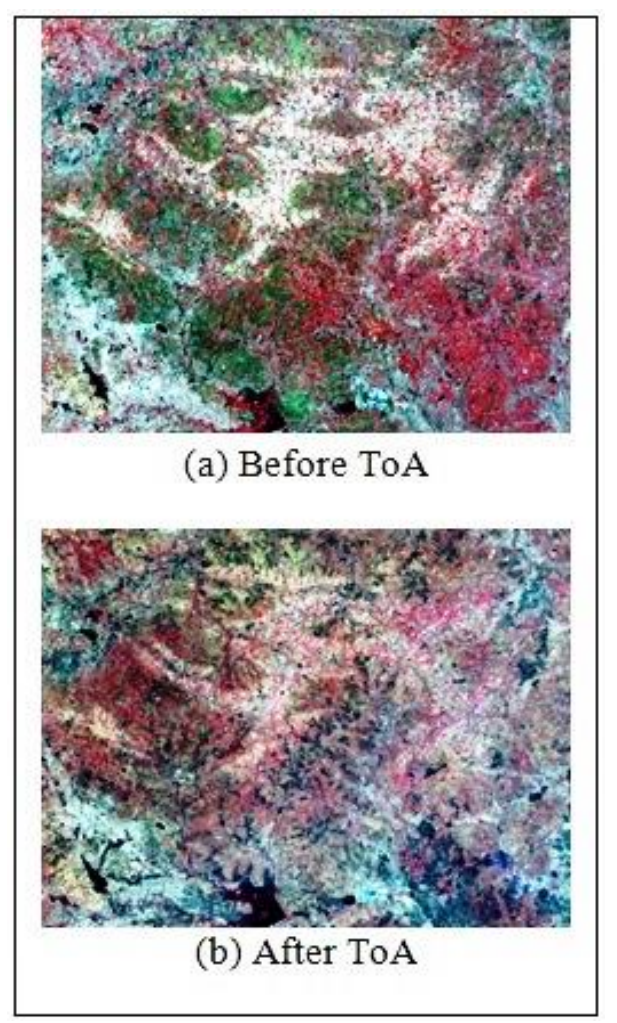

Figure 3. Illustration of correction process (ToA) of Landsat 8 OLI.

In order to determine the relationship of statistical data, the researcher used the data collected from Landsat 8 OLI to analyze the relationship together with the field work data to create equations for estimation of the above-ground carbon sequestration. The results can be explained as follows:

1) Using the DVI method, it results in the equation $\mathrm{y}=0.3184 \mathrm{e}^{0.0482 \mathrm{x}}$ and the coefficient of determination $\mathrm{R}^{2}=0.8457$ (Fig 4).

The amount of the above-ground sequestration's calculation result is 213.176 tons per Rai.

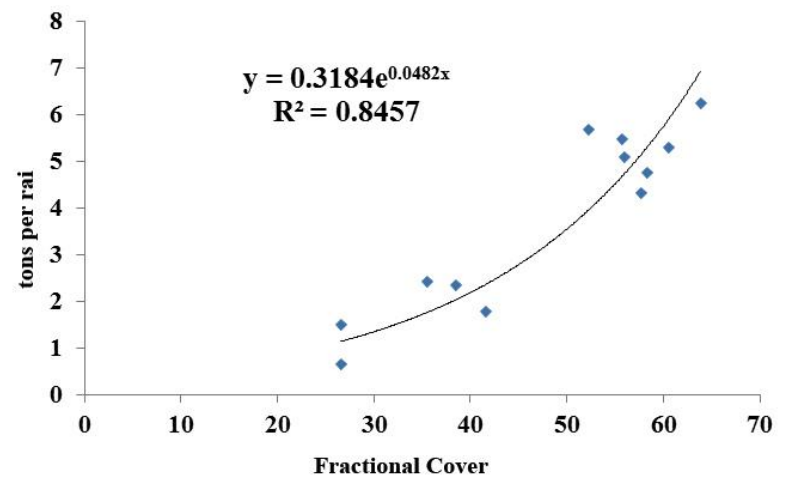

Figure 4. The equation by the DVI method.

2) Using the GVI method, it results in the equation $\mathrm{y}=0.2619 \mathrm{e}^{0.0489 \mathrm{x}}$ and the coefficient of determination $\mathrm{R}^{2}=0.8763$ (Fig 5). The amount of the above-ground sequestration calculation's result is 220.510 tons per Rai.

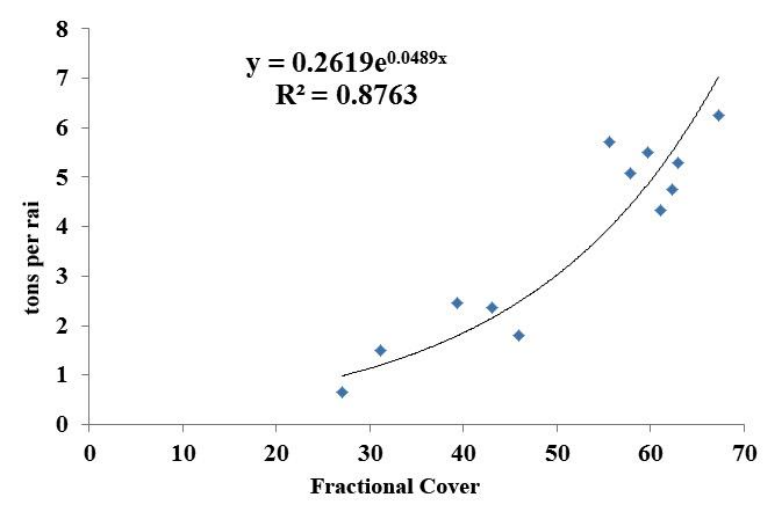

Figure 5. The equation by the GVI method.

3) Using the SR method, it results in the equation $\mathrm{y}=0.8900 \mathrm{e}^{0.0469 \mathrm{x}}$ and the coefficient of determination $\mathrm{R}^{2}=0.7748$ (Fig. 6).

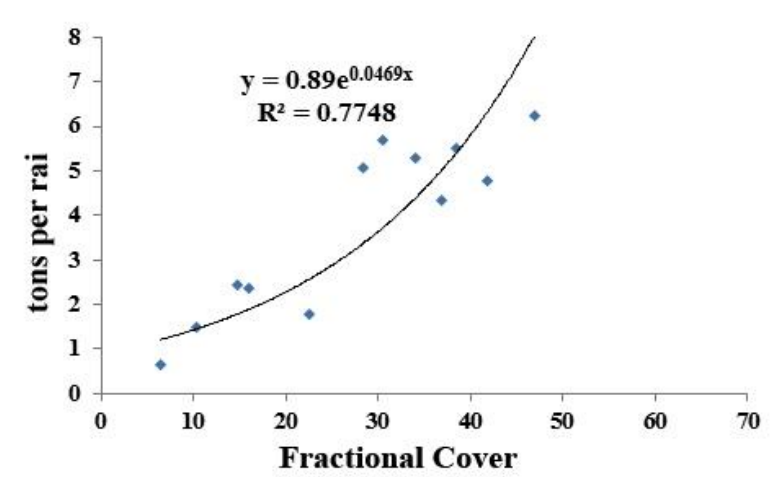

Figure 6. The equation by the SR method. 
The amount of the above-ground sequestration calculation's result is 244.229 tons per Rai.

Furthermore, the researcher also tested the statistical correctness of the above-ground carbon data collected from Landsat 8 OLI and the field work by using the Pair Sample T-test. As a result, it could be concluded that the DVI, GVI, and SR methods had 95\% confidence level of the statistical significance.

\section{Conclusion}

The study of the above-ground carbon sequestration used the data collected from Landsat 8 OLI and vegetation indices including the DVI, GVI, and SR of orchards in Sang Kho sub district, Phu Phan district, and Sakon Nakhon Province in northeast Thailand to determine the relationship between the amounts of the above-ground carbon storage (variable) and vegetation indices such as the DVI, GVI and SR. This was done collecting the data from Landsat 8 OLI (free variable) by applying 3 regression equations to calculate the relationship between the variables resulted with the best method GVI with the equation $y=0.2619 \mathrm{e}^{0.0489 \mathrm{x}}$ and the coefficient of determination $\mathrm{R}^{2}=0.8763$. However, after the Pair Sample T-test was applied, it was found that the 3 equations had $95 \%$ confidence of statistical significant level. For further studies, one of the 3 equations is able to be applied to estimate the aboveground carbon sequestration of orchards in other areas of Thailand.

\section{Acknowledgement}

This research was financially supported by the Faculty of Science Mahasarakham University.

\section{References}

[1] Office of Environmental Policy and Planning. Thailand's national greenhouse gas inventory 1994, Ministry of Science, Technology and Environment, Bangkok, 2000.

[2] Jundang, W., Puangchit, L., Diloksumpun, S.: Carbon Storage of Dry Diptero-carp Forest and Eucalypt Plantation at Mancha Khiri Plantation, Khon Kaen Province, Thai Journal of Forestry, 29 (2010), 3, 36-44.

[3] IPCC: Climate change, IPCC fourth assessment report (AR4).: In: Solomon S, Qin D, Manning $M$, Chen Z, Marquis M, Averyt KB, Tigora M, Miller HL (eds.). The physical science basis,
Cambridge University Press, Cambridge, UK/New York, 2007.

[4] Usa Klinhom, Teerawong Laosuwan, Pornchai Uttaruk , Rittirong Junggoth, Penkhae Thamsenanupap, Komgrit Wongpa- kam: Carbon Offset in forest Sector: Final Report Carbon Offset in forest Sector Project, National Research Council of Thailand (NRCT), Bangkok, 2011.

[5] Ogawa, H., Yoda, K., Ogini, K., Kira, T.: Comparative Ecological Study on Three Main Type of Forest Vegetation in Thailand, Nature and Life in Southeast Asia, 4 (1965), 49-80.

[6] Senpaseuth, P., Navanugraha, C., and Pattanakiat, S.: The Estimation of Carbon Storage in Dry Evergreen and Dry Dipterocarp Forests in Sang Khom District, Nong Khai Province, Thailand, Environment and Natural Resources Journal, 7 (2009),2, 1-11.

[7] UNFCCC: Clean development mechanism: methodologies: afforestation/Reforestation methodologies. Approved A/R Methodolo-gies. http://cdm.unfccc.int/ methodologies/ARmethodologies/ approved_ar.html. Accessed: 04 October 2013.

[8] UNFCCC: Clean development mechanism: methodologies: small scale Afforestation / reforestation CDM methodologies. Methodologies for small scale A/R CDM project activities. http://cdm.unfccc.int/methodologies/ SSCAR/ approved.html. Accessed: 04 October 2013.

[9] Chicago Climate Exchange, Forestry carbon sequestration offsets.

http://www.chicagoclimatex.com/content.jsf?id $=242$. Accessed: 05 October 2014 .

[10] Malini A. S., Somashekar R.K.: Multispectral Monitoring of Vegetation Cover of Bangalore Metropolitan Area, Global Journal of Biochemistry and Biotechnology, 2 (2013), 1, 27-32.

[11] Schlerf, M., Alzberger, C., Hill, J.: Remote sensing of forest biophysical variables using HyMap imaging spectrometer data, Remote Sens. Environ, 95 (2005), 177-194.

[12] Samaniego, L., Schulz, K. Supervised classification of agricultural land cover using a modified k-NN technique (MNN) and Landsat remote sensing imagery. Remote Sens, 1 (2009), 875-895.

[13] Solaimani, K., Snokrian, F., Tamartash, R., Banihashemi, M.: Landsat ETM+ Based Assessment of Vegetation Indices in Highland 
Environment. Journal of Advances in Developmental Research, 2 (2011), 1, 5-13.

[14] Laosuwan, T., Uttarak, P., Klinhom, U., Butthep, C., Samek, J. H., Skole, D. L.: Development of Web-GIS Application for Carbon Sequestration in Thailand, International Journal of Geoinformatics, 7 (2011), 2, 41-47.

[15] Laosuwan, T., Uttaruk, P.: Estimating Tree Biomass via Remote Sensing, MSAVI 2, and Fractional Cover Model, IETE Technical Review, 31 (2014), 5, 362-368.

[16] Dong, J., Shao, L.: Experimental Study on Deformation Properties of Unsaturated Compacted Soil Based on Digital Image Measurement, Engineering Review, 34 (2014), 3, 217-222.

[17] Wang, Y. Q., Liu, X.: Improved Support Vector Clustering Algorithm for Color Image Segmentation, Engineering Review, 35 (2015), 2, 121-129.

[18] Lu, D., Mausel, P., Brondizio, E., Moran, E.: Assessment of atmospheric correction methods for Landsat TM data applicable to Amazon basin LBA research. Int. J. Remote Sens, 23 (2002), 2651-2671.

[19] Yale University.: Converting Digital Numbers to Top of Atmosphere (ToA) Reflectance, http://cdm.unfccc.int/methodo logies/ SSCAR/ approved.html. Accessed: 04 February 2015.
[20] Irish, R.: Calibrated Landsat Digital Number (DN) to Top of Atmosphere (TOA) Reflectance Conversion. http://igett.delmar.edu/Resources/Remote\%20S ensing\%20Technology\%20Training/Calculatio n-DN_to_Reflectance_Irish_20 June08.pdf.

Accessed: 14 February 2015.

[21] Malini A. S., Somashekar R.K.: Multispectral Monitoring of Vegetation Cover of Bangalore Metropolitan Area. Global Journal of Biochemistry and Biotechnology, 2(2013) ,1, 27-32.

[22] Odindi, J. O., Bangamwabo, V., Mutanga, O.: Assessing the Value of Urban Green Spaces in Mitigating Multi-Seasonal Urban Heat using MODIS Land Surface Temperature (LST) and Landsat 8 data. Int. J. Environ. Res., 9 (2015), 1, 9-18.

[23] Schlerf, M., Alzberger, C., Hill, J.: Remote sensing of forest biophysical variables using HyMap imaging spectrometer data. Remote Sens. Environ, 95 (2005), 177-194.

[24] Portland State University. Vegetation Indices, http://web.pdx.edu/ nauna/ resources/82012_lecture1-vegetationindicies. pdf. Accessed: 20 February 2015.

[25] Harrisgeospatial Soulution.: Broadband Greenness, https://www.harrisgeo spatial.com/docs/BroadbandGreenness.html. Accessed: 29 February 2015. 